\title{
Priming with potassium solutions improves seedling growth and vigor in forage sorghum (Sorghum bicolor $\mathbf{L}$.)
}

\author{
Priyamvada Chauhan ${ }^{1 *}$, Geeta Pandey ${ }^{1}$, and Pradeep Kumar Pandey ${ }^{2}$ \\ ${ }^{1}$ Department of Seed Science and Technology, College of Agriculture, G.B. Pant University of Agriculture and \\ Technology, Pantnagar, U.S. Nagar-263145 (Uttarakhand), INDIA \\ ${ }^{2}$ Department of Genetics and Plant Breeding, College of Agriculture, G.B. Pant University of Agriculture and \\ Technology, Pantnagar, U.S. Nagar-263145 (Uttarakhand), INDIA \\ ${ }^{*}$ Corresponding author. E-mail: priyam09chauhan@gmail.com
}

Received: January 22, 2016; Revised received: July 1, 2016; Accepted: October 31, 2016

\begin{abstract}
In this study a laboratory experiment was conducted to assess the effect of different potassium priming sources on seedling growth and vigor of sorghum genotypes. Priming with $\mathrm{KH}_{2} \mathrm{PO}_{4}$ gave best results for SOG (23.052), RL (19.667) and $\mathrm{VI}(2,291.9)$. $\mathrm{KCl}$ found to be better at lower concentration (150mM) for all the characters i.e., FGP (73.11), MGT (3.90), SOG (21.776), RL (18.444) and VI (2,272.6). However, $\mathrm{KNO}_{3}$ gave better results at higher concentration (300mM) for MGT (3.11), SOG (16.779), RL (18.056) and VI (1471.0). $\mathrm{KMnO}_{4}$ was found to be better than $\mathrm{KCl}(300 \mathrm{mM})$ and $\mathrm{KNO}_{3}(150 \mathrm{mM}$ and $300 \mathrm{mM})$ for FGP (60.0), SOG (19.187), RL (19.256) and VI $(1,998.3)$. Among genotypes, CSV15 gave the best results for all the vigor indices. The interaction between genotypes and treatments was recorded to be non-significant for all the characters except FGP at 0.05 level of significance. It can be concluded that seed priming with different potassium sources showed better results over control for all the characters in different sorghum genotypes. So, it may serve as appropriate treatment for accelerating the seed vigor of sorghum.
\end{abstract}

Keywords: Potassium solutions, Potassium priming sources, Seedling growth, Seed vigor, Sorghum

\section{INTRODUCTION}

Sorghum (Sorghum bicolor L.) is the fifth most important cereal crop in the world after wheat, rice, corn, and barley. Sorghum possesses a variety of anatomical, morphological, and physiological features that enable it to survive in water-limited environments (Arslan et al., 2013). Seed Priming is widely used to improve seed vigor in various crops including sorghum. It starts some of the metabolic process to occur in germination without radicle protrusion. Various seed priming techniques have been developed to improve seed vigor in different crops like hydropriming (water), osmopriming (low water potential solutions such as polyethylene glycol), halo-priming (salt solutions) and nutrient priming (nutrient solutions like $\mathrm{K}, \mathrm{P}, \mathrm{Ca}, \mathrm{Na}$, etc.). Nutrient priming of seeds in pre-sowing treatments in an osmotic solution allows seeds to absorb water, but restricts radicle occurrence through testa until the primed seeds are sown for germination under salt stress conditions. Primed seeds usually show improved germination parameters (Hardegree and Van Vactor, 2000).

The global positive effects of the potassium treatments on the subsequent growth of the seedlings were most likely due to potassium on enhancing water uptake and affecting other unknown metabolic reactions. Potassium increases both the yield and quality of agricultural produce, and enhances the ability of plants to resist diseases, insect attacks, cold and drought stresses and other adverse conditions. It helps in the development of a strong and healthy root system and increases the efficiency of the uptake and use of $\mathrm{N}$ and other nutrients. Potassium has been described as the 'quality element', ensuring optimum quality of agricultural produce (Ujwala, 2011).

Potassium chloride is the most widely used source of potassium for agricultural crops, and $\mathrm{Cl}$ is considered as an essential micronutrient for optimal growth (Fixen, 1993). Potassium chloride has been introduced as the osmoticum to enhance germination, emergence and growth of Poaceae plants (Misra and Dwivedi, 1980). Seed priming with nitrate solutions gave better seed quality and field establishment in maize (Hanegave et al., 2011). Potassium permanganate has oxidizing properties and can act as ethylene neutralizer or an antiseptic. It helped in germination of some legume seeds stored for 20 - 44 years (Grauda et al., 2013). It is found that on-farm' seed priming with $\mathrm{KH}_{2} \mathrm{PO}_{4}$ improved fertilizer- use efficiency and increased yield and profit for different crops grown on $\mathrm{P}$ deficient soils (Ali et al., 2008). 
The most sensitive stages, for many crop species submitted to the stress conditions, are seed germination and early seedling growth (Rahimi, 2013). Therefore, the seed germination performance indicators (germinability, mean germination time, germination rate and vigor index) are very important for successful crop production. This study was also aimed to evaluate the priming effect of various potassium sources on early seed vigor enhancement in different sorghum genotypes.

\section{MATERIALS AND METHODS}

The present study was done in completely randomize design with three replications in PG Laboratory of the Department of Genetics \& Plant Breeding, G. B. Pant University of Agriculture \& Technology, Pantnagar (U. S. Nagar) to evaluate the effect of various potassium sources and levels through priming in sorghum genotypes. The experiment was conducted by using four potessium sources with different concentrations viz. $\mathrm{KCl} 150 \mathrm{mM}(\mathrm{T} 2)$ and $\mathrm{KCl} 300 \mathrm{mM}(\mathrm{T} 3), \mathrm{KNO}_{3}$ $150 \mathrm{mM}(\mathrm{T} 4)$ and $\mathrm{KNO}_{3} 300 \mathrm{mM}$ (T5), $\mathrm{KMnO}_{4} 2 \%$ (T6) and $\mathrm{KH}_{2} \mathrm{PO}_{4} 2 \%$ (T7) along with control (T1). Seeds of three sorghum genotypes i.e. CSV15, PC5 and UPC2 were stored for one year in ambient conditions. Seeds were soaked in priming solutions for 24 hrs and then dried back for four hrs before germination. The seeds were germinated in incubator at $25^{\circ} \mathrm{C}$ and were considered as germinated when the radical length reached $>1 \mathrm{~cm}$. Germination percent was recorded on each day till final count i.e. 10 days. Root length $(\mathrm{cm})$ and shoot length $(\mathrm{cm})$ were recorded by five randomly selected seedlings. Mean germination time was calculated by using following formula (Ellis and Roberts, 1981).

$\mathrm{MET}=\sum \mathrm{dn} / \sum \mathrm{n}$

Where, $\mathrm{n}$ is the number of seeds that had germinated on day $d$ and $d$ is the number of days counted from the beginning of germination. Speed of germination was calculated by using the equation given by Maguire (1962).

Data was analyzed by two way analysis of variance using OP-STAT software technique developed by HAU and the least significant difference test at $5 \%$ probability level was used to compare treatment means.

\section{RESULTS AND DISCUSSION}

Significant differences among genotypes were obtained for final germination percentage (FGP) across the priming treatments. Comparing the genotypes, highest germination percent was recorded for CSV15 (77.66) and lowest for UPC2 (61.0) in control. Nascimento (2003) concluded that differences in the response of seeds to priming have been due to the osmotica (priming), duration of priming, seed maturity, variety, and environmental conditions. Among treatments, maximum FGP was recorded in $\mathrm{KCl} 150 \mathrm{mM}$ (73.11) followed by $\mathrm{KH}_{2} \mathrm{PO}_{4}(67.88) . \mathrm{KCl}$ and $\mathrm{KNO}_{3}$ gave good results at lower concentrations i.e. at $150 \mathrm{mM}$ for

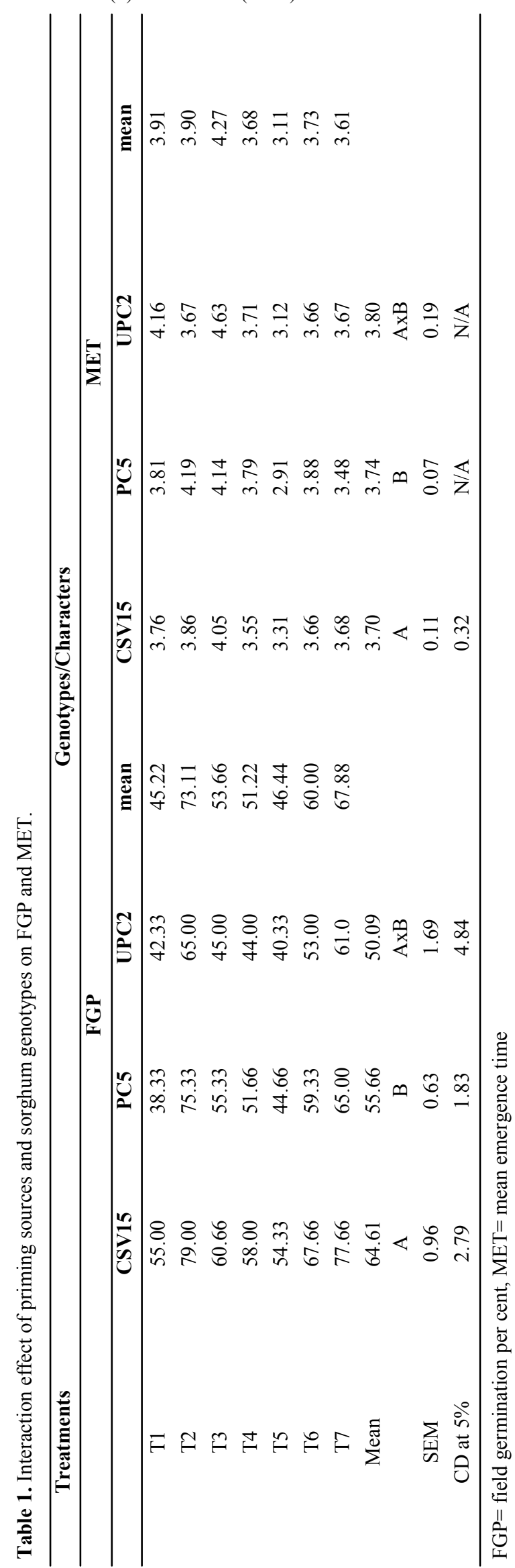




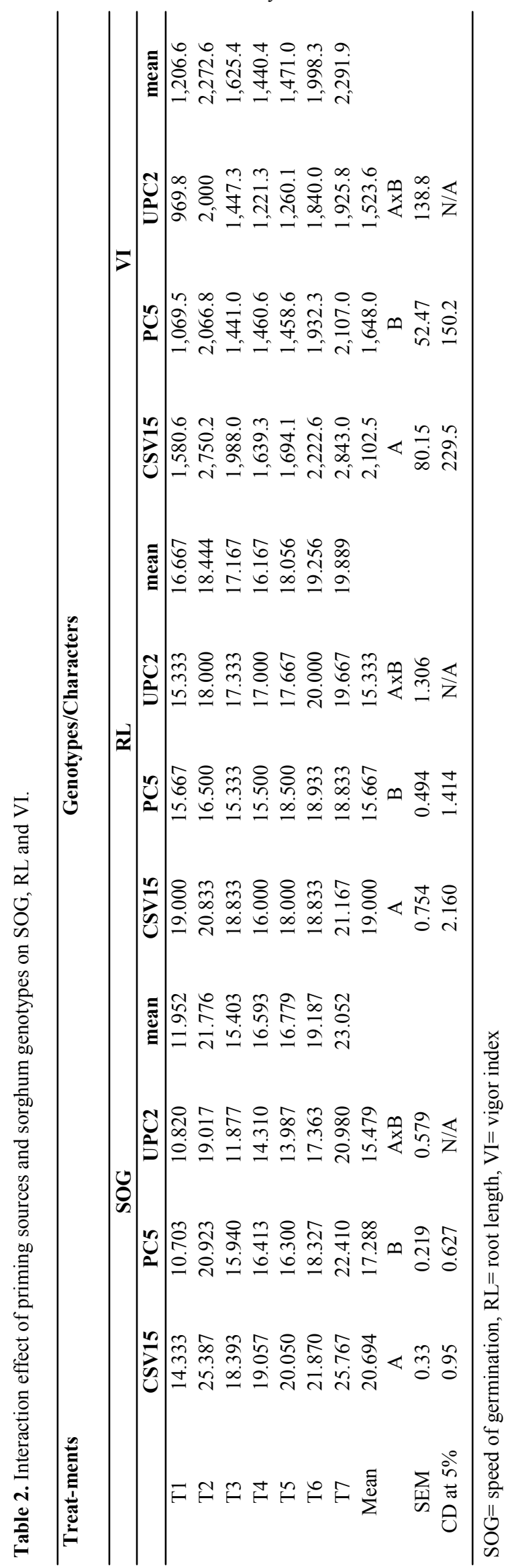

FGP and found to be highly significantly differing with each other and with other treatments (Table 1). Same results were found by Khan et at. (2014) in sorghum who concluded that soaking seed with osmopriming agents like $\mathrm{KCl}$ and $\mathrm{KNO}_{3}$ in low concentrations enhances germination and rapid seed emergence.

Mean emergence time (MET) was found to be minimum in seeds treated with $\mathrm{KNO}_{3} 300 \mathrm{mM}$ (3.11) followed by $\mathrm{KH}_{2} \mathrm{PO}_{4}$ (3.61) for all the genotypes which were significantly different from each other. For MGT, significant differences among genotypes were not obtained across all priming treatments. Priming with $\mathrm{KCl}$ exhibited no good results for MET in comparison to control at both the concentration levels, while $\mathrm{KMnO}_{4}$ was found to be better than $\mathrm{KCl}$ for MET. All treatments gave significantly different results for all the genotypes at 0.05 level of significance (Table 1).

A statistically significant difference of treatments and interaction were found among the varieties for speed of germination at $\mathrm{p}<0.05$ (Table 2). Speed of germination was affected by the varieties in which significantly different responses were obtained. The least speed of germination was recorded by UPC2 where as the maximum speed of germination were obtained from CSV15. The genotype $\mathrm{x}$ priming treatment interactions on the speed of germination was not significant at $\mathrm{p}<0.05$ (Table 2). Trend of speed of germination in different varieties revealed that the greatest speed of germination in CSV15 (25.767) occurred when the seeds primed with $\mathrm{KH}_{2} \mathrm{PO}_{4}$ as compared to the control despite it was at par with priming with $\mathrm{KCl} 150 \mathrm{mM}$ (25.387). Increased in germination rate in primed seeds over unprimed seeds is also in accordance with the findings of Afzal et al. (2005) who reported that emergence percentage and mean emergence time (MET) were significantly affected by most of priming treatments in wheat. Bove et al. (2001) reported that faster germination is associated with earlier activation of various metabolic enzymes and preparation of the embryo axis for elongation during the germination process. Nascimento and West (1998) concluded that priming also reduces the adherence of seed coat which may permit to emerge out radical without any resistance. So this may also contribute for an increase in the rate of germination as indicated in Table 2 for various priming treatments.

The genotypes showed significant differences for root length $(\mathrm{cm})$ at $\mathrm{p}<0.05$ (Table 2). However, interaction between genotype $\mathrm{x}$ priming was not significant for this trait. The longest root length was demonstrated by genotype CSV15 by priming with $\mathrm{KH}_{2} \mathrm{PO}_{4}$ (21.167) followed by $\mathrm{KCl} 150 \mathrm{mM}$ (20.833). Different seed priming treatments affected the early vigor of sorghum genotypes significantly in terms of root length. Seeds primed in solution of $\mathrm{KH}_{2} \mathrm{PO}_{4}$ had the maximum root length (19.889), followed by treatment with $\mathrm{KMnO}_{4}$ (19.256) and $\mathrm{KCl} 150 \mathrm{mM}$ (18.444) in all the genotypes. The minimum root length was observed in seeds 
treated with $\mathrm{KNO}_{3} 150 \mathrm{mM}$ which was similar to the control (16.167) followed by $\mathrm{KCl} 300 \mathrm{mM}$ (17.167). The increased root length with $\mathrm{KH}_{2} \mathrm{PO}_{4}$ of might be due to increased $\mathrm{P}$ content both inside the seeds which can lead to better establishment of seedlings (Ros et al., 1997).

Seedling vigor index of the 10 days old seedlings were significantly differing among priming treatments at $\mathrm{P}<$ 0.05 (Table 2). The priming medium $\mathrm{KH}_{2} \mathrm{PO}_{4}$ produced the highest seedling vigor index $(2,291.9)$ over the varieties followed by $\mathrm{KCl} 150 \mathrm{mM}(2,272.6)$ and $\mathrm{KMnO}_{4}$ (1.998.3). This finding also was similar with Umair et al. (2013) who reported that osmo priming with $\mathrm{KH}_{2} \mathrm{PO}_{4}$ improved vigor Index of mungbean (Vigna radiata L.) and concluded that early emergence in treated seeds may be due to the fasterpp production of germination metabolites and better genetic repair. The minimum seedling vigor index was in control $(1,206.6)$ where non-primed seeds were used. Maximum vigor index was recorded for the genotype CSV15 $(2,102.5)$ followed by PC5 $(1,648.0)$ and UPC2 $(1,523.6)$ over all the treatments. Interaction between genotype and treatments found to be nonsignificant for this character (Table 2).

\section{Conclusion}

Osmopriming with $\mathrm{KH}_{2} \mathrm{PO}_{4}$ was found to be the most promising priming technique for seed vigor enhancement in sorghum which improved all the characters over control and other treatments viz., FGP (67.88), MET (3.61), SOG (23.052), RL (19.889) and VI $(2,291.9)$. However, other priming treatments were also found to be better than that of untreated seeds. $\mathrm{KCl}$ and $\mathrm{KNO}_{3}$ gave better results at lower concentrations $(150 \mathrm{mM})$ than most of the characters i.e., MET (3.90 and 3.68, respectively), SOG (21.776 and 16.593, respectively), RL (18.444 and 16.593, respectively) and VI (2,272.6 and 1,440.4, respectively). Among all three genotypes studies, CSV 15 performed better for all characters, i.e., FGP (64.61), MET (3.70), SOG (25.767), RL (19.000) and VI (2,102.5). From the present study, it may be concluded that seed priming with different potessium sources can enhance the seedling establishment and quality of sorghum genotypes.

\section{REFERENCES}

Afzal, I., Basra, S.M.A. and Iqbal, A. (2005). The effects of seed soaking with plant growth regulators on seedling vigor of wheat under salinity stress. Journal of Stress Physiology and Biochemistry, 1(1): 6-14

Ali, S., Khan, A.R., Mairaj, G., Arif, M., Fida, M. and Bibi, S. (2008). Assessment of different crop nutrient management practices for yield improvement. Aust. J. Crop Sci., 2(3): 150-157

Arslan, M., Erdurmuş, C. and Çakmakçi, S. (2013). Effects of $\mathrm{NaCl}$ concentrations on germination and early seedling growth of silage sorghum (Sorghum bicolor (L.) Moench) varieties on different textured soils. Journal of Food, Agriculture and Environment, 11:474-476

Bove, J., Jullien, M. and Grappin, P. (2001). Functional genomics in the study of seed germination. Genome Biology, 3:1002.1-1002.5

Ellis, R.A. and Roberts, E.H. (1981). The quantification of ageing and survival in orthodox seeds. Seed Sci. Technol., 9: 373-409

Fixen, P.E. (1993). Crop responses to chloride. Advances in Agronomy, 50: 107-150

Grauda, D., Lapina, L., Jansone, B., Jansons, A. and Rashal, I. (2013). Recovering genetic resources of some legume species of Latvian origin by plant tissue culture. Proc. Latvian Academy of Sci., 67:224- 228

Hanegave, A.S., Hunje, R., Nadaf, H.L., Biradarpatil, N.K., and Uppar, D.S. (2011). Effect of seed priming on seed quality of maize (Zea mays L.). Karnataka Journal Agricultural Sciences, 24: 237-238

Hardegree, S.P. and Van vactor, S.S. (2000). Germination and emergence of primed grass seeds under field and simulated-field temperature regimes. Annals of Botany, 85: 379-390

Khan, K., Gul, Ullah, Z., Afsar, A., Uddin, I. and Ullah, H. (2014). Effect of different osmopriming sources and levels on germination and root length of sorghum, Weekly Science Research Journal, 1 (25)

Maguire, J.D. (1962). Speed of germination-aid in selection and evaluation for seedling emergence and vigour. Crop. Science, 2: $176-177$

Misra, N.M. and Dwivedi, D.P. (1980). Effects of pre-sowing seed treatments on growth and dry-matter accumulation of high yielding wheat under rain-fed conditions. Indian Journal of Agronomy, 25: 230-234

Nascimento, M.W. (2003). Muskmelon seed germination and seedling development in response to seed priming. Scientia Agricola, 60(1): 71-75

Nascimento, W.M. and West, S.H. (1998). Priming and seed orientation affect emergence and seed coat adherence and seedling development of muskmelon transplants. Horticultural Science, 33: 847-848

Rahimi, A. (2013). Seed priming improves the germination performance of cumin (Cuminum syminum L.) under temperature and water stress. Industrial Crops and Products, 42: 454-460

Ujwala R.M. (2011). Interaction of micronutrients with major nutrients with special reference to potassium. Karnataka J. Agric. Sci., 24 (1): 106-109

Umair, A.,Ali, S., Sarwar, M., Bashir, K., Tareen, M.J. and Malik, M.A. (2013). Assessment of some priming techniques in mungbean (Vigna radiata): a green house study. Pakistan J. Agric. Res., 26(4): 265-274 